\title{
National Radiologic Technology Licensure Examination Performance: Predicting Success using Discriminant Analysis
}

\author{
Mark M. Alipio ${ }^{\mathrm{a}, \mathrm{b}}$ \\ March 2020 \\ ${ }^{a}$ Davao Doctors College, General Malvar St., Davao City 8000, Philippines \\ ${ }^{b}$ University of Southeastern Philippines, Mintal, Davao City 8000, Philippines
}

\begin{abstract}
This study was designed to identify variables that might be used as predictors for success on the national Radiologic Technology licensure examination. The census sample consisted of 2,036 graduates of a baccalaureate Radiologic Technology program in 2016, 2017, and 2018 from 24 higher education institutions (HEIs) in the Philippines. The investigators examined 12 variables to determine their predictive value for the national Radiologic Technology licensure examination success. Grades in all year levels of Radiologic Technology course were the four best predictors. Results of the discriminant analysis identified seven significant predictor variables leading to successful classification of 99.9 percent of all the passing graduates and 99.8 percent of the failing graduates in the national Radiologic Technology licensure examination. The use of this discriminant function to identify high-risk students has the advantage of early identification of failing. The large amount of 92 percent variance in the national RT licensure examination accounted for in this study may substantiate the claim of high accuracy of the discriminant function used. This is the first study to discriminate passing from failing graduates in the national RT licensure examination based on the selected predictor variables and the astounding precision of classifying graduates is a remarkable result for HEIs included in the analysis.
\end{abstract}

Keywords: Discriminant Analysis; Education; Licensure Examination; Performance; Philippines; Predicting Success; Radiologic Technology

\section{Introduction}

Radiological procedures have become the gold standard for the detection, diagnosis, and treatment of diseases (Onega et al., 2013). Among these procedures are X-ray examinations, Magnetic Resonance Imaging scans, Computed Tomography scans, Radiation Therapy, and Nuclear Medicine scans. Radiologic Technologists, also known as Medical Radiation Technologists, perform these procedures in hospitals, clinics, medical laboratories, and private practice (Yumul, 2012). They use their knowledge and expertise in patient's handling, anatomy, physiology, physics, pathology, and radiology to develop optimal radiologic techniques or plans, assess patients, and evaluate resulting radiographic images. Physicians rely on the information provided by Radiologic Technologists to determine the diagnosis and treatment of their patients (Shaterjalali, Changiz, \& Yamani, 2018). 
The level of judgment needed, the intricacy of procedures performed, and the amount of responsibility that Radiologic Technologists assume depend primarily on the amount of experience and education they have. Moreover, substantial to high-quality health care is the assurance that healthcare professionals performing radiological procedures can carry out their responsibilities in a proficient manner. Thus, radiologic technologists of demonstrated competence are of prime importance.

In the Philippines, the standard requirement for an entry-level position as a Radiologic Technologist is a four-year degree in Bachelor of Science in Radiologic Technology and a certification of passing the National Licensure Examination for Radiologic Technologists granted by the Professional Regulation Commission (Yumul, 2012). The primary objective of the licensure examination is to obtain reliable and valid information as to whether examinees acquire the technical capability required for the profession. Technical proficiency includes technical knowledge, the ability to apply such knowledge skillfully and with good judgment and an understanding of professional responsibility (Alipio, 2020; Nasir, Noordin, Farheeza, \& Nordin, 2011).

Recognizing the value credited in the licensure exam results, predicting graduates' success on the National Licensure Examination for Radiologic Technologists is an essential quality measure of the program. Accurate predictions of National Licensure Examination for Radiologic Technologists success become valuable because they can heighten faculty and student awareness, reduce anxiety, and foster productive study behaviours. Hence, the main objective of the study was to determine significant predictors of success on the National Licensure Examination for Radiologic Technologists and the extent to which success can be accurately predicted.

\subsection{Predictor Variables}

The predictor variables were chosen based on the review of the literature and input from members of the Radiologic Technology Curriculum Committee and the deans or heads for student services.

Included in the analysis were the following:

- High School GWA

- Entrance Examination Score

- General Education Subjects GWA

- Clinical Performance

- Internship Theoretical Exam Score

- Freshman RT Professional Subjects GWA

- Sophomore RT Professional Subjects GWA

- Junior RT Professional Subjects GWA

- Senior RT Professional Subjects GWA

- Years to Complete Program

- Probation History

- Transfer from other School

The last two variables (Probation History and Transfer from other School) were coded one (1) for yes and zero (0) for no. 


\section{Methods}

Data were collected anonymously from student records on 2,160 students who graduated from baccalaureate Radiologic Technology program in 2016, 2017, and 2018 from 24 higher education institutions (HEIs) in the Philippines. A total of 124 subjects were eliminated from the study because of missing data. The 2,036 remaining subjects were classified into two groups based on passing or failing the National Licensure Examination for Radiologic Technologists. A total of 12 predictor variables were examined using discriminant analysis.

\section{Results}

The means, standard deviations, and frequency distributions for the variables included in the study are shown in Table 1. Pearson Product-Moment Correlation Coefficients for RT licensure examination success with other variables are also reported in Table 1. All variables except general education subjects GWA, clinical performance, probation history, and transfer from other school were significantly correlated with passing or failing the RT licensure examination. Freshman RT professional subjects GWA showed the highest correlation with RT licensure examination success $(\mathrm{r}=.762)$, followed by RT professional subjects GWA in senior $(r=.745)$, junior $(r=.742)$, and sophomore levels $(r=.723)$. Internship theoretical exam score, high school GWA, and entrance examination score also were highly correlated.

Table 1. Descriptive statistics and correlations with passing the licensure examination

\begin{tabular}{llll}
\hline Variable & Mean & $\begin{array}{l}\text { Standard } \\
\text { deviation }\end{array}$ & $\begin{array}{l}\text { Correlation with } \\
\text { passing the exam }\end{array}$ \\
\hline High School GWA & 84.23 & 1.85 & $.601^{*}$ \\
Entrance Examination Score & 81.65 & 3.91 & $.549^{*}$ \\
General Education Subjects GWA & 85.42 & 4.14 & .056 \\
Clinical Performance & 83.86 & 4.27 & .101 \\
Internship Theoretical Exam Score & 76.91 & 2.7 & $.672^{*}$ \\
Freshman RT Professional Subjects GWA & 81.17 & 5.25 & $.762^{*}$ \\
Sophomore RT Professional Subjects GWA & 78.76 & 5.63 & $.723^{*}$ \\
Junior RT Professional Subjects GWA & 82.91 & 5.56 & $.743^{*}$ \\
Senior RT Professional Subjects GWA & 82.12 & 4.24 & $.745^{*}$ \\
Years to Complete Program & 5.23 & 1.03 & -.168 \\
\hline Variable & Options & Frequency & Correlation with \\
& & & passing the exam \\
\hline Probation History & Never & 1,562 & -.023 \\
Transfer from other School & Once or more & 474 & \\
Licensure Examination & No & 1,752 & .104 \\
\hline
\end{tabular}


The Box $M$ test was not significant (Box $M=32.32, p=.393$ ), which indicates that group variance was equivalent and the assumption of homogeneity of covariance was met. The Wilk's lambda for the two (pass and fail) groups' means was significant at the $p=.0001$ level for the discriminant analysis. This established the fact that the graduates who passed and those who failed had different means for the variables; therefore, the discriminant function was significant.

The squared canonical correlation for the discriminant function was .921, indicating that a little more than 92 percent of the shared variance between groups and predictors was accounted for by the discriminant function in the final analysis.

High school GWA, entrance examination score, internship theoretical exam score, freshman RT professional subjects GWA, sophomore RT professional subjects GWA, junior RT professional subjects GWA, and senior RT professional subjects GWA all loaded on this function for the final analysis (Table 2).

Freshman RT professional subjects GWA had the highest loading on the discriminant function, followed by RT professional subjects GWA in senior, junior, and sophomore levels.

Table 2. Correlations of predictors with discriminant function

\begin{tabular}{lc}
\hline Variable & Loading \\
\hline High School GWA & .823 \\
Entrance Examination Score & .826 \\
General Education Subjects GWA & .241 \\
Clinical Performance & .234 \\
Internship Theoretical Exam Score & .831 \\
Freshman RT Professional Subjects GWA & .909 \\
Sophomore RT Professional Subjects GWA & .859 \\
Junior RT Professional Subjects GWA & .876 \\
Senior RT Professional Subjects GWA & .881 \\
Years to Complete Program & -.341 \\
Probation History & -.121 \\
Transfer from other School & .109 \\
\hline
\end{tabular}

NOTE. Italicized variables were interpreted as loading on the discriminant function.

Overall, more than 99 percent of graduates were correctly categorized by the discriminant analysis (Table $3)$. Because only 52.6 percent of the graduates would be correctly categorized by chance alone, these percentages represent a substantial improvement over chance. More than 99 percent of the students who passed the RT licensure examination were classified correctly by the discriminant analysis, whereas more than $99 \%$ percent of the students who failed were classified correctly. Because only 45 percent and 55 percent of these graduates, respectively, would be classified correctly by chance, this is an important improvement, especially for the passing group. 
Table 3. Classification summary for the discrimination function

\begin{tabular}{llll}
\hline & \multicolumn{2}{l}{ Predicted group } & \\
\cline { 2 - 3 } Actual group & Fail \# $(\%)$ & Pass \# $(\%)$ & Total \# $(\%)$ \\
\hline Fail & $1,118(99.8)$ & $2(0.2)$ & $1,120(100.0)$ \\
Pass & $1(0.1)$ & $915(99.9)$ & $916(100.0)$ \\
Total & $1,119(55.0)$ & $917(45.0)$ & $2,036(100.0)$ \\
\hline
\end{tabular}

\section{Discussion}

The variables in this study were chosen in part because of their success as predictors in previous studies and in part because of faculty experience. The discriminant analysis developed in this study was highly accurate in separating the graduates who passed the national RT licensure examination from those who failed the examination. Fewer than 0.2 percent of the graduates were incorrectly classified by the discriminant function. Because only 52.6 percent of the graduates would be correctly categorized by chance alone, these percentages represent a substantial improvement over chance. In addition, it is noteworthy that 99.8 percent of those who failed the national RT licensure examination were accurately classified by this discriminant function. Only 55 percent of these students would be classified correctly by chance, so this procedure yields significantly better prediction for the failing group than chance alone. Furthermore, the successful classification of 99.9 percent of all the passing graduates and 99.8 percent of the failing graduates represents the most precise categorizing found in licensure examination studies to date, especially for the subjects who failed. This is the first study to discriminate passing from failing graduates in the national RT licensure examination based on the selected predictor variables and the astounding precision of classifying graduates is a remarkable result for HEIs included in the analysis.

Although 12 predictors were included in the discriminant analysis, those that played the greatest role in classifying graduates were grades in RT professional subjects in the first to fourth year levels, internship theoretical exam score, high school GWA, and entrance examination score. Freshman RT professional subjects GWA had the highest loading on the discriminant function, followed by RT professional subjects GWA in senior, junior, and sophomore levels.

\section{Limitations}

Several limitations must be considered when interpreting these findings. The subjects were all graduates of one baccalaureate Radiologic Technologic program, so the results may not be generalizable to graduates of other programs. Although a little over 92 percent of the variance in passing or failing was accounted for by this discriminant function, the other 8 percent of the variance was unaccounted for. Although this is a better variance value when compared to other national licensure examination programs discriminant analyses, it still suggests that one or more important predictors may have been omitted from the analysis. 


\section{Implications}

Several implications were drawn based on the findings of the study. The results of this investigation suggest that results on the national RT licensure examination can be predicted with a high level of accuracy by using readily available student data. It is especially notable that all this data is available by the end of the second semester of the fourth year level. This allows approximately five months between identifying a student as a high risk for failure and graduation, during which time faculty can provide remediation. The use of this discriminant function to identify high-risk students has the advantage of early identification of failing. The large amount of variance in the national RT licensure examination accounted for in this study may substantiate the claim of high accuracy of the discriminant function used.

\section{References}

Alipio, M. M. (2020). Predicting Academic Performance of College Freshmen in the Philippines using Psychological Variables and Expectancy-Value Beliefs to Outcomes-Based Education: A Path Analysis.

Alipio, M. M. (2020). Academic Adjustment and Performance among Filipino Freshmen College Students in the Health Sciences: Does Senior High School Strand Matter.

Cohen, J. W. (1988). Statistical power analysis for the behavioral sciences (2nd edn). Hilldales, NJ: Lawrence Erlbaum Associates, 79-81.

Nasir, A., Noordin, M., Farheeza, D., \& Nordin, M. (2011). Technical skills and non-technical skills: predefinition concept. Proceedings of the IETEC'11 Conference, Kuala Lumpur, Malaysia.

Onega, T., Anderson, M. L., Miglioretti, D. L., Buist, D. S., Geller, B., Bogart, A., ... Yankaskas, B. C. (2013). Establishing a gold standard for test sets: variation in interpretive agreement of expert mammographers. Academic radiology, 20(6), 731-739. doi:10.1016/j.acra.2013.01.012

Shaterjalali, M., Changiz, T., \& Yamani, N. (2018). Optimal clinical setting, tutors, and learning opportunities in medical education: A content analysis. Journal of education and health promotion, 7, 130. doi:10.4103/jehp.jehp_56_18

Yumul, R. (2012). Introduction to Radiologic Technology with Science, Technology and Society (1st ed). Ermita, Manila: Educational Publishing House. 